\title{
Molecular Evidence for the Wide Distribution of Two Lineages of Terrestrial Green Algae (Chlorophyta) over Tropics to Temperate Zone
}

\author{
Ladislav Hodač, ${ }^{1}$ Christine Hallmann, ${ }^{1}$ Helen Rosenkranz, ${ }^{2}$ \\ Fabian Faßhauer, ${ }^{1}$ and Thomas Friedl ${ }^{1}$ \\ ${ }^{1}$ Experimental Phycology and Culture Collection of Algae (SAG), Georg August University Göttingen, Untere Karspüle 2a, \\ 37073 Göttingen, Germany \\ ${ }^{2}$ School of Biological Sciences, University of Bristol, Woodland Road, Bristol BS8 1UG, UK
}

Correspondence should be addressed to Ladislav Hodač, lhodac@uni-goettingen.de

Received 29 April 2012; Accepted 29 July 2012

Academic Editors: J. McLaughlin, M. Rossetto, S. Sabater, and W. Shi

Copyright ( 2012 Ladislav Hodač et al. This is an open access article distributed under the Creative Commons Attribution License, which permits unrestricted use, distribution, and reproduction in any medium, provided the original work is properly cited.

\begin{abstract}
Phylogenetic analyses of $18 \mathrm{~S}$ rDNA sequences from environmental clones and culture strains revealed a widespread distribution of two subaerial green algal lineages, Jenufa and Xylochloris, recently described from rainforests in southeast Asia. A new lineage of Jenufa (Chlorophyceae), most closely related to or even conspecific with J. minuta, was formed by sequences of European origin. Two more lineages of Jenufa were formed by three additional sequences from Ecuador and Panama. The other lineage was a close relative of Xylochloris irregularis (Trebouxiophyceae), probably representing a new species of the genus and distinct from the only so far described species, $X$. irregularis. It comprised two distinct clades each containing almost identical sequences from Germany and Ecuador. Analyses of the new sequences for both genera allowed to presume a preference of J. minuta to subaerial growth on rock or artificial hard substrates combined with a remarkable adaptation to extended periods of darkness, whereas Xylochloris may preferably occur on tree bark or in the soil.
\end{abstract}

\section{Introduction}

The neutral dispersal model [1] suggests that microorganisms do not exhibit biogeography, that is, they are so small that no distribution barriers exist for them. This has been subject of debates by several authors, that is, geographic distribution was found in ciliates [2] and some microalgae [3]. A recent study based on $18 \mathrm{~S}$ rDNA sequence comparisons provided evidence for endemism in an Antarctic habitat, that is, several new independent lineages of green algae were found in the benthos of an Antarctic lake $[4,5]$. However, caution needs to be applied because there may still be an insufficient number of sequences available for many groups within the green algae. A lineage may appear "endemic" only as long as no other close relatives to it are known and this may easily change with the availability of new sequences from close relatives. In contrast to benthic freshwater algae, subaerial algae may be widely dispersed due to their remarkable adaptation to fast changing and adverse environmental conditions. Their resting cysts may easily survive transportation over long distances in the air being resistant to drought, high as well as low light intensities, and high UV radiation, for example, due to the presence of thickened cell walls or light protection pigments [6-9].

Recently, subaerial microalgae from southeast Asian tropical rainforest habitats gained increased interest by a series of studies [10-14] which lead to the establishment of two new genera of green algae, Jenufa [13] and Xylochloris [14]. Both genera appeared as somehow distant to any known genera of green algae, despite a taxon sampling as large as possible that has been applied in the $18 \mathrm{~S}$ rDNA sequence analyses of both studies. The environmental sequencing approach extends the data pool available for diversity comparisons and may enable us to assess distribution patterns of protists $[15,16]$. In the present study we took the advantage of an extended taxon sampling available 
through new $18 \mathrm{~S}$ rDNA environmental sequences that we obtained from our own ongoing studies which focus on changes in the algal diversity of certain terrestrial habitats along gradients of abiotic parameters in Europe (Germany, Ukraine) and South America (Ecuador). In addition, a variety of closely related environmental sequences have become available from GenBank. Here we demonstrate the presence of new lineages for both recently described genera, Jenufa (Chlorophyceae) and Xylochloris (Trebouxiophyceae), their wide distribution over long geographic distances, and that both differ in their preferences towards certain substrates.

\section{Materials and Methods}

2.1. Origin of Analysed Sequences. The analysed sequences and culture strains were provided by several our own ongoing studies which focus on the algal diversities of various terrestrial habitats, see Table 1 . They were derived from soil, tree bark or stone surfaces samples at four temperate habitats and one tropical habitat (Table 1). The majority of sequences were from environmental 18S rDNA clone libraries (334-1761 base pairs long), three from cultured strains which were accessioned by the SAG culture collection as strains SAG 2378, SAG 2382, and SAG 2383. Soil and tree bark samples originating from Germany were collected within the frame of the German Biodiversity Exploratories project (http://www.biodiversity-exploratories.de), for project description see Fischer et al. [17] (Figure 1(a)). Samples of biofilms dominated by green algae were investigated from the surface of sandstone samples within the framework of another study, focusing on wall sections of the castle "Burg Gleichen," near Gotha (Thuringia, Germany) [18]. The biofilm samples were either from a sun-exposed wall area (Figure 1(b)) or from the inner face of a scale from a dark basement vault (Figure 1(c)). Samples from an even less light-exposed locality were from the concrete walls inside a World War II bunker monument on the North Sea offshore island Helgoland, Germany (Figures $1(\mathrm{~d})$ and $1(\mathrm{e}))$. Here the algal biofilms were exposed to extended periods of darkness because light is available from fluorescent tubes only during guided tours for tourists, that is, $1.5 \mathrm{hrs}$ per day and around 8 months per years. The soil sample from Ukraine was from the arid steppe zone (Chernomorskiy Biosphere Reserve). The soil and tree bark samples from South America originated from the tropical mountain rain forest in southern Ecuador along an elevation transect at $1000 \mathrm{~m}, 2000 \mathrm{~m}$, and $3000 \mathrm{~m}$ above sea level (a.s.l.) corresponding to three different regions (Table 1; Figures $1(\mathrm{f})$ and $1(\mathrm{~g})$ ).

2.2. Microscopy and rDNA Sequence Determination. Microscopic observations of cultures were conducted using an Olympus BX60 microscope (Tokyo, Japan) with Nomarski DIC optics and an attached ColorView III camera (Soft Imaging System, Münster, Germany). Micrographs were processed using Cell ${ }^{\wedge} \mathrm{D}$ image software (Soft Imaging System, Münster, Germany). The detailed experimental procedures on how the $18 \mathrm{~S}$ rDNA clone libraries and cultures were established will be described elsewhere. Briefly, DNA was extracted from environmental samples using MoBio PowerSoil DNA isolation Kit (MoBio Laboratories Inc., Carlsbad, CA, USA) and from mechanically disrupted cultured algal cells using Invisorb Spin Plant Mini Kit (Stratec, Berlin, Germany). Almost full-length $18 \mathrm{~S}$ rDNA sequences were amplified from the cultures and European environmental samples with primers preferentially binding to green algal rDNAs, for the samples from Ecuador a region from about 350 base pairs upstream of the $3^{\prime}$ end of $18 \mathrm{~S}$ rDNA downstream to the $26 \mathrm{~S}$ rDNA which included the ITS2 rDNA for DNA barcoding purposes was amplified. Either almost full $18 \mathrm{~S}$ rDNA sequences were obtained or partial sequences comprising either the hypervariable regions V2, V3 and V4 (European environmental samples) or hypervariable regions V8 and V9 regions (Ecuador environmental samples) of $18 \mathrm{~S}$ rDNA $[19,20]$. The newly determined sequences are available from GenBank under the accession numbers JQ988923 and JQ988943.

2.3. Phylogenetic Analyses. The newly determined sequences were used in database queries using BLAST [21] at NCBI (http://www.ncbi.nlm.nih.gov/) to retrieve their closest neighboring sequences available from public sequence data bases (state in March 2012). In addition, the newly determined and their retrieved closest relative sequences were compared to a broad selection of green algal sequences which was available in the internal $18 \mathrm{~S} \mathrm{rDNA}$ sequence database of our laboratory and is maintained in the ARB program (version 05.05.26, 2004, http://www.arb-home.de) [22]. This database was updated with all currently available $18 \mathrm{~S}$ rDNA sequences from green algae. The comparisons identified sequences of both genera, Jenufa and Xylochloris, as well as their next relatives. Potential chimeras were identified by Bellerophon [23] and excluded from the analyses. The almost full $18 \mathrm{~S}$ rDNA sequences of Jenufa, Xylochloris, and their close relatives were aligned in two separated data sets, that is, together with representatives of all known lineages from the two green algal classes, Chlorophyceae and Trebouxiophyceae. First the sequences were aligned with MAFFT version 6 [24] online (http://mafft.cbrc.jp/alignment/server/index.html) in order to identify and exclude intron positions. Then the sequences from each class were aligned with MUSCLE online (http://www.ebi.ac.uk/Tools/msa/muscle). The alignments were carefully checked for possible misaligned positions by eye in BioEdit [25]. The final alignment of Chlorophyceae comprised 97 sequences and 1790 positions (742 variable/535 parsimony informative sites), the alignment of Trebouxiophyceae included 99 sequences and 1807 positions (710 variable/497 parsimony informative sites). Based on the AIC criterion in jModelTest 0.1.1 [26], the GTR + + + I nucleotide substitution model was selected as to fit best both alignments. ML phylogenies were obtained from RAxML 7.0.4 [27]. Confidence values for the obtained groups (edge support) were inferred from rapid bootstrapping algorithm (1000 replicates) as implemented in RAxML. Bayesian posterior probabilities for internal nodes were obtained 


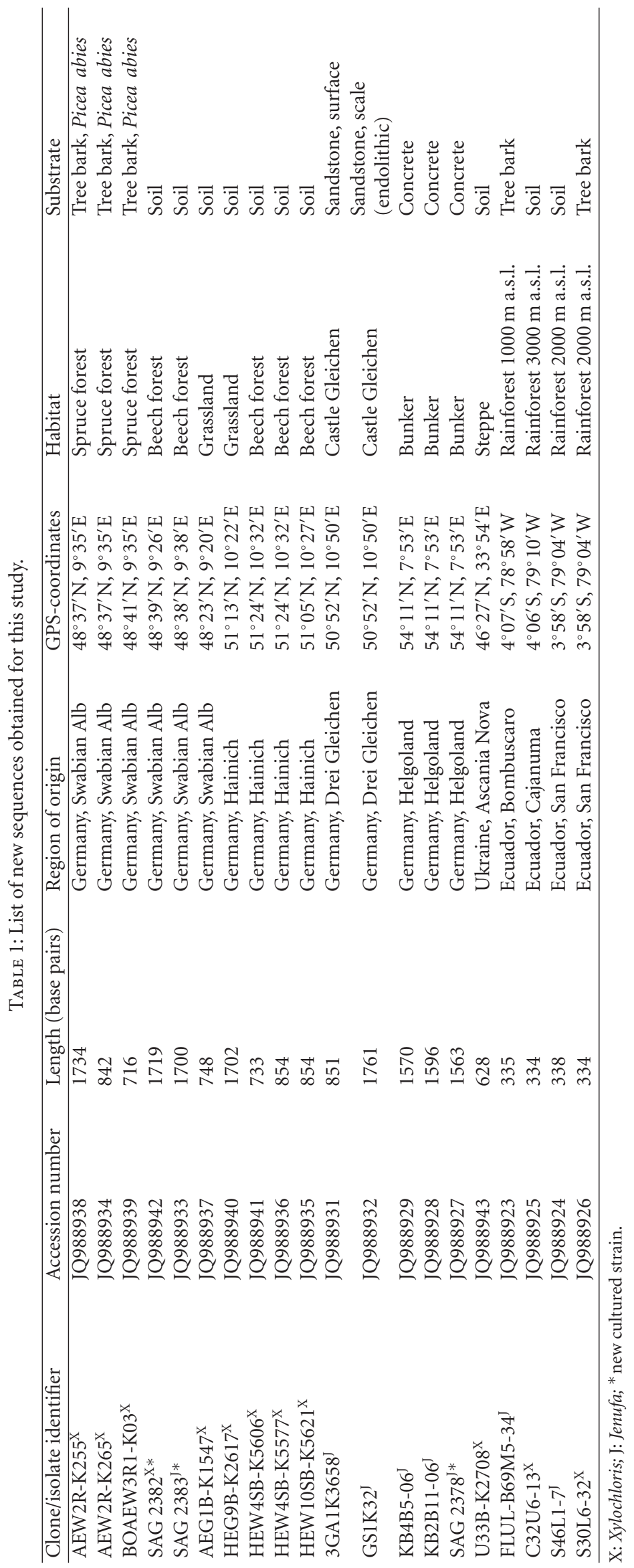




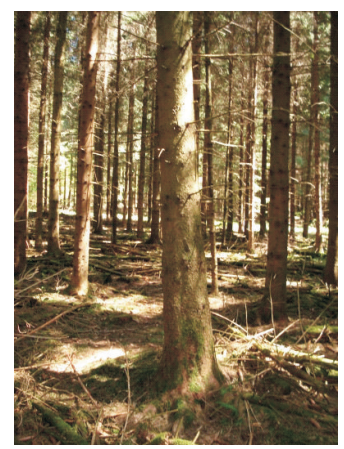

(a)

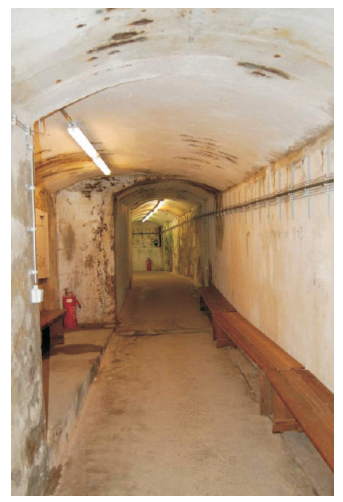

(d)

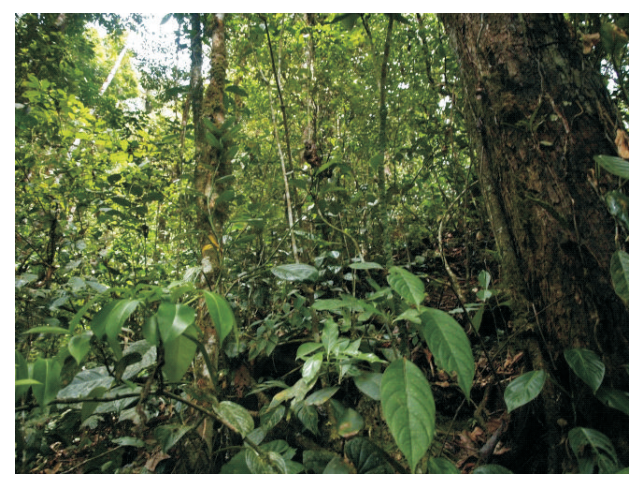

(f)

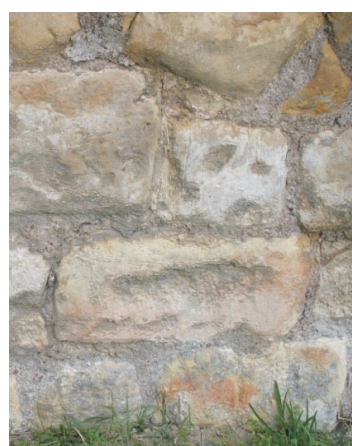

(b)

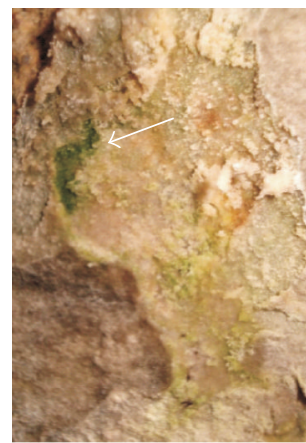

(c)

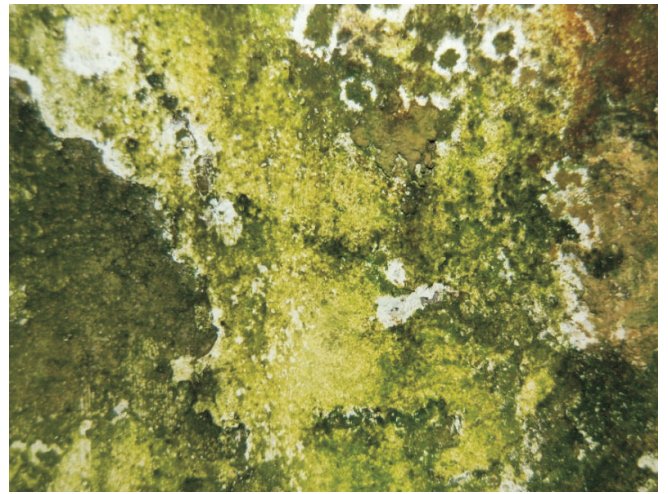

(e)

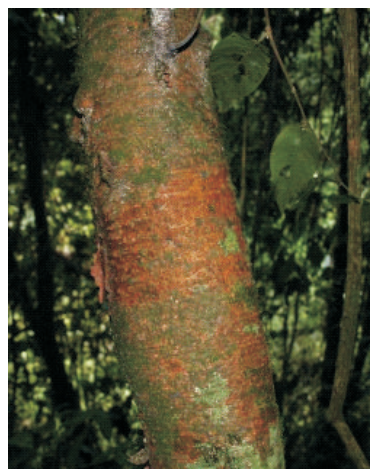

(g)

Figure 1: Sampling sites. (a) Young spruce forest in the Swabian Alb, (b-c) wall sections of castle Gleichen (Germany), (b) sun-exposed wall area, (c) inner face of a scale from a dark basement vault (the white arrow shows the sampled green biofilm), (d-e) biofilm samples from concrete walls in a World War II bunker on the North Sea offshore island Helgoland, (e) sampled green biofilm in detail, (f-g) tropical submountain rainforest in Ecuador (the study site in Bombuscaro, $1000 \mathrm{~m}$ a.s.l.), and (g) green biofilms on tree bark in detail.

using MrBayes 3.2 [28]. Two MCMC runs for four million generations each with one cold and three heated chains using the GTR $+\Gamma+\mathrm{I}+\mathrm{COV}$ evolutionary model (parameters were estimated from the data) were performed with trees sampled every 100 generations.

For comparisons of European with Ecuadorian environmental clones for which different regions of the 18S rDNA were determined (see above), only the hypervariable regions V8/V9 of the $18 \mathrm{~S}$ rDNA could be used because they represent an overlapping sequence region available in both data sets (European data set comprised the full sequences whereas the Ecuadorian one the partial ones). Then only sequences of closest relatives were used for the phylogenetic analyses, that is, the investigated datasets comprised less than 10 sequences and were only about 300 base pairs long. Bioneighborjoining distance phylogenies based on Jukes-Cantor genetic distances and 1000 bootstrap replicates were computed in the program SeaView version 4 [29]. The parsimony analysis was conducted using DNAPARS as implemented in SeaView with 10 times randomization of the sequence order and 1000 bootstrap replicates. Evolutionary distances among selected sequences were computed as p-distances in MEGA5 [30] with ambiguous alignment positions removed for each sequence pair. 
2.4. Multivariate Statistical Analysis. In order to compare the clones originating from the different substrates within Europe (tree bark, soil, and stone surfaces) Nonmetric Multidimensional Scaling (NMDS) analysis based on genetic distances was computed. The analysis was conducted on the matrix of Jukes-Cantor genetic distances (within alignments comprising hypervariable regions $\mathrm{V} 2, \mathrm{~V} 3$, and V4 of the $18 \mathrm{~S} \mathrm{rDNA}$ ) as implemented in the program package PAST version 2.12 [31]. The reliability of the resulting ordination was examined by checking the stress values from Shepard-plot. The alignment comprising the new sequences of Jenufa minuta relatives included 8 sequences and 658 positions (Figure $2(\mathrm{~d})$ ), whereas the other comprising the new sequences of Xylochloris relatives included 10 sequences and 595 positions (Figure $3(\mathrm{~d})$ ).

\section{Results and Discussion}

3.1. Jenufa Lineage. The $18 \mathrm{~S}$ rDNA phylogeny revealed the position of several of the obtained new environmental sequences and the three cultured isolates into the immediate vicinity of the genera Jenufa (Chlorophyceae, Figures 2(a), 2(b), and 2(d); Figure S1 in Supplementary Material available online at doi:10.5402/2012/795924) and Xylochloris (Trebouxiophyceae, Figures 3(a), 3(b), and 3(d); Figure S2 in Supplementary Material). We recovered sequences assigned to Jenufa from environmental clone libraries from Germany (soil, hard substrates), Ukraine (soil), and Ecuador (soil, tree bark) (Table 1). The full European environmental sequences and the culture strains formed a well-supported monophyletic cluster ( $\mathrm{p}$-distances $0.001-0.004$ ) closely related to Jenufa minuta. The p-distances among European sequences and $J$. minuta $(0.016-0.019)$ were about two times lower than between J. minuta and J. perforata (0.038). The partial environmental sequences from Ecuador constitute a lineage by its own positioned between J. minuta and J. perforata, but without significant bootstrap support (Figure 2(d)). As already discussed previously [13], Jenufa may represent a distinct probably new lineage of Chlorophyceae of still unresolved relationship to the orders Sphaeropleales and Chlamydomonadales. Within the $18 \mathrm{~S}$ rDNA phylogeny presented here, Jenufa is placed together with Golenkinia on the very basis of Chlamydomonadales, although without statistical support ((ML/BI-69/0.83) in Figure 2(a); Figure S1 in Supplementary Material). In contrast, in Bayesian tree topology, Jenufa- and Golenkinia-clades formed a lineage independent of the Chlamydomonadales and Sphaeropleales.

The light-microscopic observations on the two available culture strains SAG 2383 and SAG 2378 were in agreement with their assignment to Jenufa inferred from the $18 \mathrm{~S}$ rDNA phylogenetic analyses. Both strains exhibited morphological characters as previously described for $J$. minuta and J. perforata (Figure 4(a)). Bot species were found indistinguishable from each other without the use of a confocal microscope and the analysis of cell wall structures [13].
3.2. Xylochloris Lineage. Other new environmental sequences and the sequence of strain SAG 2382 were closely neighboring to Xylochloris irregularis (Trebouxiophyceae) in the 18S rDNA phylogenetic analyses, but without significant bootstrap support (Figure 3(b)). The p-distances among the full European sequences and $X$. irregularis (0.031-0.035) were slightly smaller than those between the two previously described species of Jenufa (Chlorophyceae) which may imply that the European sequences and SAG 2382 represent a species independent of $X$. irregularis. The Xylochloris clade comprised environmental clones from soils and tree bark from Germany, Singapore, and Ecuador (Figure 3(d)). The addition of new sequences supported a sister-group relationship of Xylochloris with a clade comprising of environmental clones from cold-fumarole soils of the Andes [32] and two culture strains from terrestrial habitats in Germany assigned to Dictyochloropsis (Figure 3(b), Figure S2 in Supplementary Material). The latter clade was well supported in bootstrap tests, whereas its sister-group relationship with Xylochloris was only supported in BI analyses. Strain SAG 2382 shared several morphological characters with X. irregularis [14], that is, the presence of a pyrenoid, the lobed chloroplast in vegetative cells, similar cell size, and the irregular cell shape. However, the strain also exhibited distinguishing characters of its own, namely, the presence cylindrical as well as spherical autospores at the same time (Figures 4(b)$4(d)$ ).

3.3. Substrate Preferences of Jenufa and Xylochloris. Jenufa (Chlorophyceae) and Xylochloris (Trebouxiophyceae) represent distinct lineages of terrestrial green algae without any known members from freshwater habitats. Despite Jenufa and Xylochloris were detected in both habitats, soils, and tree barks; in the tropics, the sequence analysis of their closest relatives from Europe suggests a pattern reflecting different substrate preferences for both genera. In our study Jenufa was recovered from hard substrates, except for one isolate (SAG 2383) established from soil. The hard substrates were epilithic biofilms (surface of bunker walls on Helgoland, outer surface of walls of castle Gleichen, walls of Altamira cave in Spain) as well as endolithic biofilms (rocks in Piora Valley/1,965 m a.s.l./Swiss Alps [33], or and the upper side of wall scales on castle Gleichen). Although the NMDS analysis (Figure 5) of European partial sequences did not point out any clear groupings due to substrate type (endolithic versus epilithic/soil), the second ordination axis indicated variation among sequences due to different light intensities at the sampling sites. This may be seen among Jenufa sequences from the Helgoland bunker monument. Two sequences, (KB2B11-06 and SAG 2378, originating from two sites of low irradiance within the bunker were genetically closer than both to another Jenufa sequence, KB4B5-06, from a site of three times higher irradiance (HR unpublished results). In addition, the genetic differences between two Jenufa sequences, 3GA1K3658 from epilithic and GS1K32 from endolithic habitats of the Gleichen castle sandstone walls, may be explained by adaptation to different light intensities as well, as pointed out by the NMDS-plot (Figure 5). The 


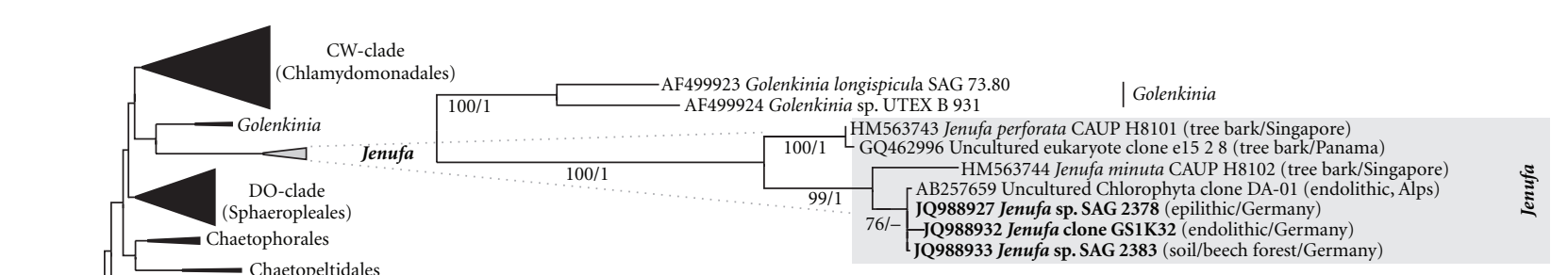

(b)

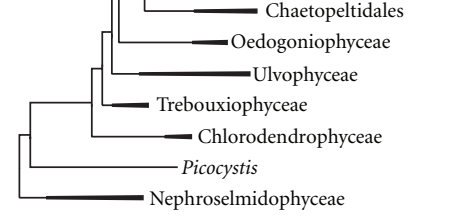

(a)

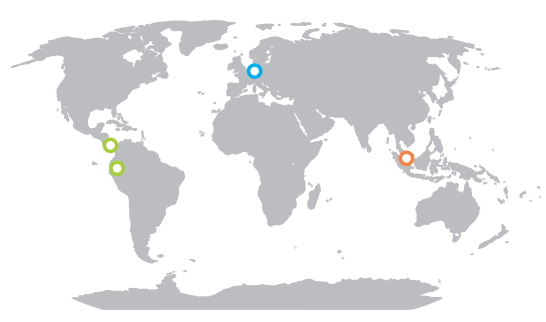

(c)

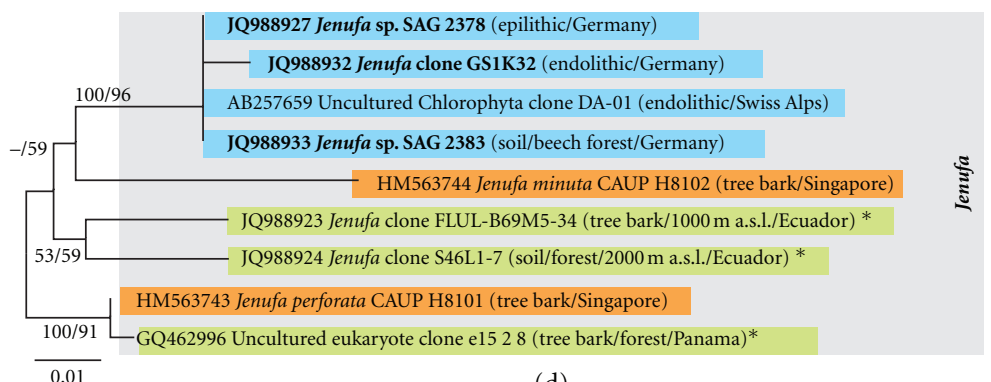

(d)

FIgURE 2: (a) Schematic 18S-based phylogenetic tree of the Chlorophyceae showing the position of sequences assigned to Jenufa minuta, (b) Jenufa/Golenkinia-clades in detail shown as a section of the full 18S rDNA ML-phylogenetic tree (Figure S1 in Supplementary Material), (c) world map with dots representing regions where Jenufa sequences were detected, and (d) BioNJ-tree based on partial $18 \mathrm{~S}$ sequences (hypervariable regions V8 and V9). Colors in figures (c) and (d) indicate three geographical regions where Jenufa occurs (orange-southeast Asia, green-south and Latin America, blue-Europe). Names in bold represent specimens analysed as both partial- and full-length 18S rDNA sequences.

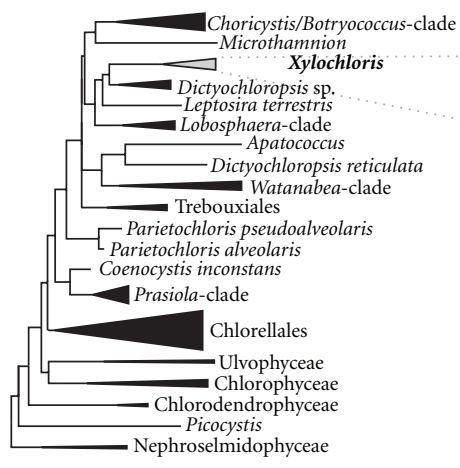

(a)

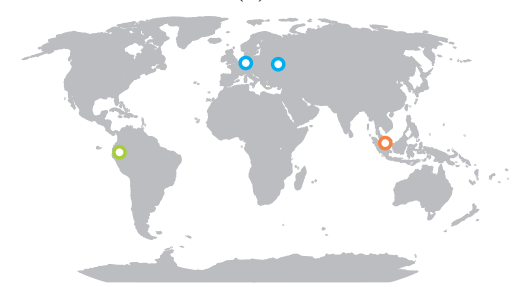

(c)

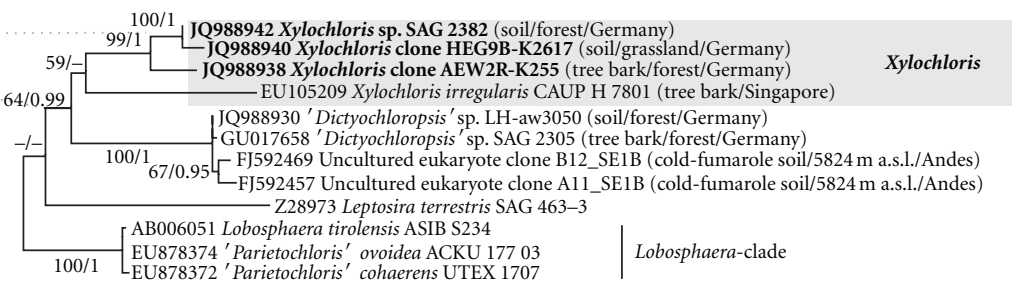

(b)

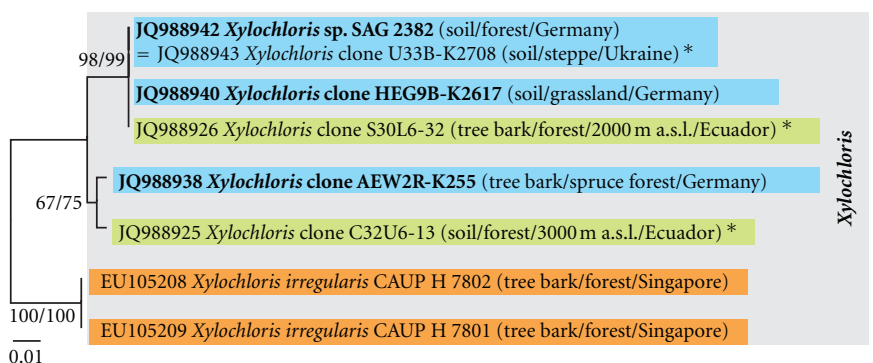

(d)

FIgURE 3: (a) Schematic 18S-based phylogenetic tree of the Trebouxiophyceae showing the placement of sequences assigned to Xylochloris, (b) the clade including Xylochloris irregularis and its closest relatives from Europe shown as a section of the full 18S rDNA ML-phylogenetic tree of the Trebouxiophyceae (Figure S2), (c) world map with dots representing regions where Xylochloris sequences were detected, and (d) BioNJtree based on partial $18 \mathrm{~S}$ sequences (hypervariable regions V8 and V9). Colors in Figures (c) and (d) indicate three geographical regions where Xylochloris occurs (orange-southeast Asia, green-South and Latin America, blue-Europe). Names in bold represent specimens analysed as both partial- and full-length $18 \mathrm{~S}$ rDNA sequences. 


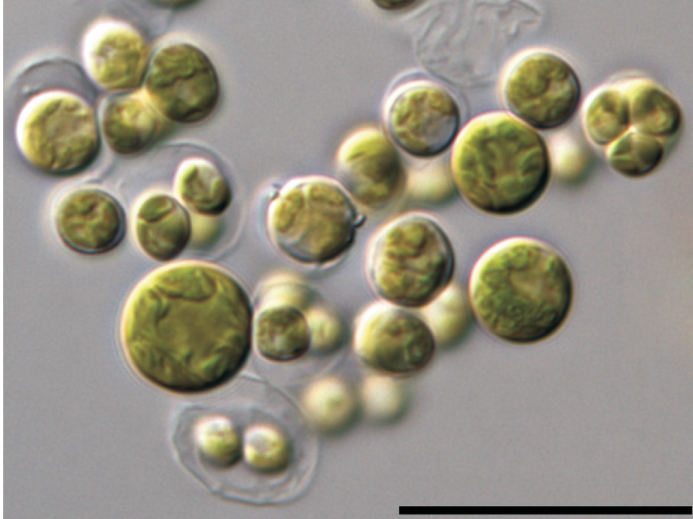

(a)

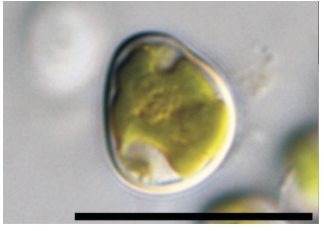

(b)

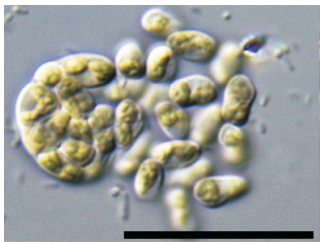

(c)

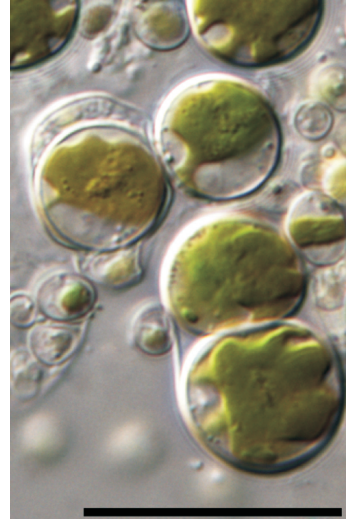

(d)

Figure 4: Microphotographs of the strains SAG 2383 (a) and SAG 2382 (b-d), (a) vegetative cells and autospores of the European Jenufa strain SAG 2383 isolated from a soil sample from Swabian Alb (Germany), (b) vegetative cell of Xylochloris strain SAG 2382 exhibiting the presence of one pyrenoid, (c) irregular cylindrical to oval autospores typical for the strain, and (d) vegetative cells with lobed margins of the chloroplast. Scale bar represents $20 \mu \mathrm{m}$.

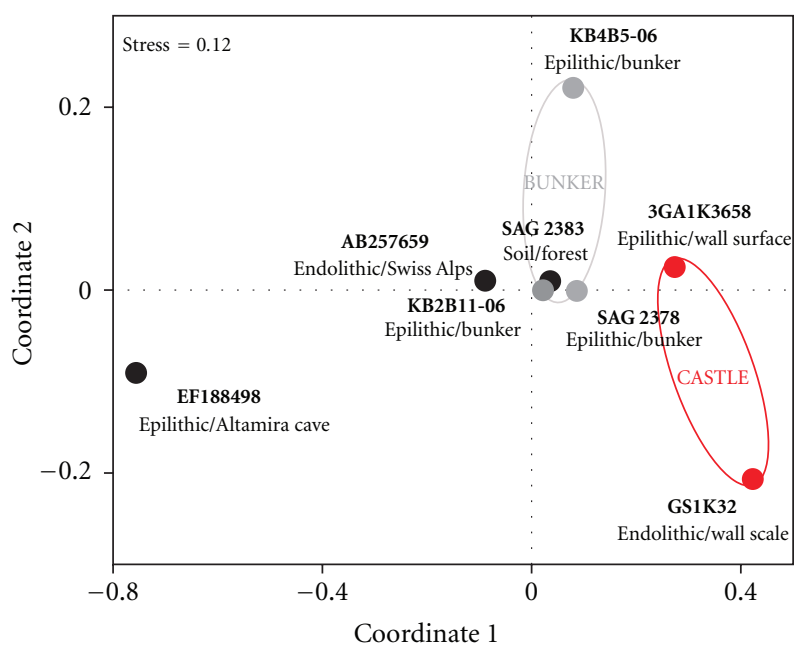

FIgURE 5: Nonmetric multidimensional Scaling (NMDS) diagram. The ordination analysis based on the Jukes-Cantor genetic distances among 6 environmental clones and 2 isolates representing sequences of Jenufa minuta detected in Europe on various hard substrates. For the analysis, $18 \mathrm{~S}$ partial sequences comprising hypervariable regions $\mathrm{V} 2, \mathrm{~V} 3$, and V4 were used. The red-colored points represent sequences from the walls of castle Gleichen/Germany, the blue ones are from the bunker on Helgoland, an offshore island in the North Sea. For the corresponding accession numbers of the sequences see Table 1 .

newly determined Xylochloris sequences were all recovered from tree bark as well as from soils. The NMDS analysis pointed out a separation of two groups of very closely related sequences from tree bark against from those from soils (Figure 6). These two groups may represent even two separate taxa at the level of species or below, as already discussed above. Members of both groups were recovered also from Ecuador, hence both may be widespread as well.

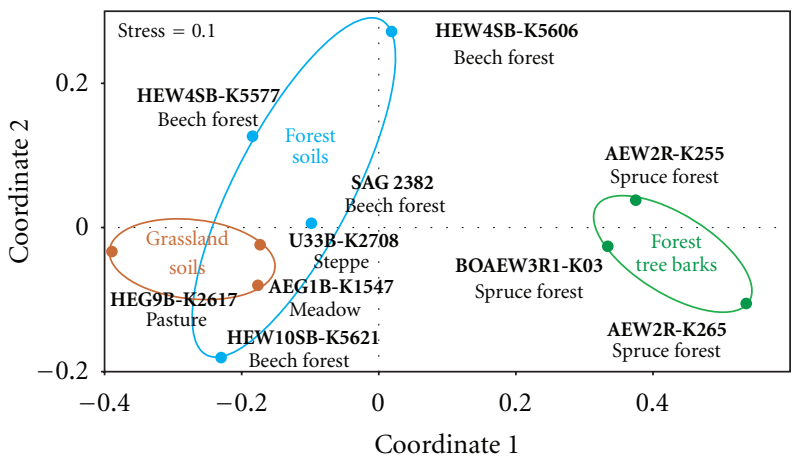

Figure 6: Nonmetric multidimensional scaling (NMDS) diagram. The ordination based on Jukes-Cantor genetic distances among 9 environmental clones and 1 isolate representing a yet undescribed European species of the genus Xylochloris. For the analysis $18 \mathrm{~S}$ partial sequences comprising hypervariable regions V2, V3, and V4 were used. The colors encode for three different habitats: green — tree bark, blue—forest soil, brown—grassland soil. For the corresponding accession numbers of the sequences see Table 1 .

3.4. Identification of Environmental rDNA Clones Using New Cultured Isolates. A high $18 \mathrm{~S}$ rDNA sequence similarity between strains of closely related terrestrial green algae from tropics and temperate habitats has already been presented recently [13]. Two cultured isolates of J. minuta from the tropics were found closely related to hitherto unidentified environmental clones from the Swiss Alps. This example shows that unidentified environmental clones may become identified as soon as cultures of close relatives become available, at least at the generic level if a morphologybased species or generic concept is applied. In our study we revealed two new isolates, SAG 2378 and SAG 2383, whose sequences were almost identical (p-distances 0.0010.004) to the environmental clones from the Swiss Alps. Another case where environmental clones became identified 
due to the availability of culture strains was found in the "Dictyochloropsis" clade, sister with Xylochloris in the Trebouxiophyceae (Figure 3(d)). Due to the very low genetic distances (p-distances 0.001- 0.005) present within the clade, the strains of Dictyochloropsis from tree barks in Germany and the environmental clones from the high Andes mountains (Chile) may be regarded as member of a single species which again exhibits a wide geographic distribution. The genetic distances between the Andes clones/Dictyochloropsis pairs were even shorter (0.003-0.004) than between both Andes environmental clones (0.005). In conclusion, for a better understanding of the biogeography of terrestrial microalgae, it seems to be of crucial importance not only to sequence environmental clones from somehow exotic or extreme habitats, but also to establish and sequence cultures from seemingly well-investigated regions like central Europe. For the studies on biogeography of terrestrial algae we are still faced with the lack of sufficient molecular data to compare new findings to, because the most diversity evidences from either central Europe or many other geographical regions relies on morphological observations only (e.g., [34-37]). We expect the situation to change in the future through extended application of the next generation sequencing (e.g., 454-pyrosequencing) concentrated on hypervariable regions of the $18 \mathrm{~S}$ rDNA [38].

\section{Abbreviations}

BioNJ: Bioneighbor-joining

CS: chlorophyte superclades including

Chlamydomonadales and

Sphaeropleales

BI: $\quad$ Bayesian inference

ML: Maximum likelihood

MP: Maximum parsimony

NMDS: Nonmetric multidimensional scaling.

\section{Acknowledgments}

This study would not have been possible without the stipend of the DAAD extended to L. Hodač. This work was supported by two Grants from the German Research Foundation (DFG) extended to T. Friedl (Contract no. FR 905/16-1 and FR 905/17-1) and a Grant from the German Federal Ministry of Education and Research (BMBF) extended to T. Friedl (Contract no. UKR 08/038). Parts of the work were supported by the USA National Science Foundation (DEB0529737) to Louise A. Lewis, University of Connecticut, in collaboration with T. Friedl. T. Friedl and H. Rosenkranz thank Kathrin I. Mohr for initiating and supervising the study of algal biofilms of the Helgoland bunker, T. Friedl thanks Igor Y. Kostikov for provision of the opportunity to study samples from the steppe zone of Ukraine within the project BMBF UKR 08/038. C. Hallmann acknowledges the financial support provided by the Deutsche Bundesstiftung Umwelt (DBU) extended to M. Hoppert, Göttingen. The authors acknowledge provision of environmental sequences determined by a student summer course in 2011 (project FoLL of Göttingen University). They also thank two anonymous reviewers for their critical comments on the paper.

\section{References}

[1] T. Fenchel and B. J. Finlay, "The ubiquity of small species: patterns of local and global diversity," BioScience, vol. 54, no. 8, pp. 777-784, 2004.

[2] W. Foissner, A. Chao, and L. A. Katz, "Diversity and geographic distribution of ciliates (Protista: Ciliophora)," Biodiversity and Conservation, vol. 17, no. 2, pp. 345-363, 2008.

[3] M. Řezáčová and J. Neustupa, "Distribution of the genus Mallomonas (Synurophyceae) - ubiquitous dispersal in microorganisms evaluated," Protist, vol. 158, no. 1, pp. 29-37, 2007.

[4] B. Lawley, S. Ripley, P. Bridge, and P. Convey, "Molecular analysis of eukaryotic diversity in Antarctic soils," Applied and Environmental Microbiology, vol. 70, no. 10, pp. 5963-5972, 2004.

[5] A. De Wever, F. Leliaert, E. Verleyen et al., "Hidden levels of phylodiversity in Antarctic green algae: further evidence for the existence of glacial refugia," Proceedings of the Royal Society B, vol. 276, no. 1673, pp. 3591-3599, 2009.

[6] U. Karsten, T. Friedl, R. Schumann, K. Hoyer, and S. Lembcke, "Mycosporine-like amino acids and phylogenies in green algae: Prasiola and its relatives from the Trebouxiophyceae (Chlorophyta)," Journal of Phycology, vol. 41, no. 3, pp. 557566, 2005.

[7] T. Řezanka, M. Temina, A. G. Tolstikov, and V. M. Dembitsky, "Natural microbial UV radiation filters-mycosporine-like amino acids," Folia Microbiologica, vol. 49, no. 4, pp. 339-352, 2004.

[8] L. Gustavs, A. Eggert, D. Michalik, and U. Karsten, "Physiological and biochemical responses of green microalgae from different habitats to osmotic and matric stress," Protoplasma, vol. 243, no. 1, pp. 3-14, 2010.

[9] N. Häubner, R. Schumann, and U. Karsten, "Aeroterrestrial microalgae growing in biofilms on facades-response to temperature and water stress," Microbial Ecology, vol. 51, no. 3, pp. 285-293, 2006.

[10] M. Eliáš, Y. Němcová, P. Škaloud, J. Neustupa, V. Kaufnerová, and L. Šejnohová, "Hylodesmus singaporensis gen. et sp. nov., a new autosporic subaerial green alga (Scenedesmaceae, Chlorophyta) from Singapore," International Journal of Systematic and Evolutionary Microbiology, vol. 60, no. 5, pp. 1224-1235, 2010.

[11] M. Eliáš, J. Neustupa, and P. Škaloud, "Elliptochloris bilobata var. corticola var. nov. (Trebouxiophyceae, Chlorophyta), a novel subaerial coccal green alga," Biologia, vol. 63, no. 6, pp. 791-798, 2008.

[12] J. Neustupa, Y. Němcová, M. Eliáš, and P. Škaloud, “Kalinella bambusicola gen. et sp. nov. (Trebouxiophyceae, Chlorophyta), a novel coccoid Chlorella-like subaerial alga from Southeast Asia," Phycological Research, vol. 57, no. 3, pp. 159-169, 2009.

[13] Y. Němcová, M. Eliáš, P. Škaloud, L. Hodač, and J. Neustupa, "Jenufa gen. nov.: a new genus of coccoid green algae (chlorophyceae, incertae sedis) previously recorded by environmental sequencing," Journal of Phycology, vol. 47, no. 4, pp. 928-938, 2011. 
[14] J. Neustupa, M. Eliáš, P. Škaloud, Y. Němcová, and L. Šejnohová, "Xylochloris irregularis gen. et sp. nov. (Trebouxiophyceae, Chlorophyta), a novel subaerial coccoid green alga," Phycologia, vol. 50, no. 1, pp. 57-66, 2011.

[15] J. Šlapeta, D. Moreira, and P. López-García, “The extent of protist diversity: insights from molecular ecology of freshwater eukaryotes," Proceedings of the Royal Society B, vol. 272, no. 1576, pp. 2073-2081, 2005.

[16] V. Edgcomb, W. Orsi, J. Bunge et al., "Protistan microbial observatory in the Cariaco Basin, Caribbean. I. Pyrosequencing vs Sanger insights into species richness," ISME Journal, vol. 5, no. 8, pp. 1344-1356, 2011.

[17] M. Fischer, O. Bossdorf, S. Gockel et al., "Implementing large-scale and long-term functional biodiversity research: the Biodiversity Exploratories," Basic and Applied Ecology, vol. 11, no. 6, pp. 473-485, 2010.

[18] C. Hallmann, D. Fritzlar, L. Stannek, and M. Hoppert, "Ascomycete fungi on dimension stone of the Burg Gleichen, Thuringia," Environmental Earth Sciences, vol. 63, no. 7-8, pp. 1713-1722, 2011

[19] J. M. Neefs and R. De Wachter, "A proposal for the secondary structure of a variable area of eukaryotic small ribosomal subunit RNA involving the existence of a pseudoknot," Nucleic Acids Research, vol. 18, no. 19, pp. 5695-5704, 1990.

[20] J. C. Lee and R. R. Gutell, "A comparison of the crystal structures of eukaryotic and bacterial SSU ribosomal RNAs reveals common structural features in the hypervariable regions," PLoS ONE, vol. 7, no. 5, Article ID e38203, 2012.

[21] S. F. Altschul, T. L. Madden, A. A. Schäffer et al., "Gapped BLAST and PSI-BLAST: a new generation of protein database search programs," Nucleic Acids Research, vol. 25, no. 17, pp. 3389-3402, 1997.

[22] W. Ludwig, O. Strunk, R. Westram et al., "ARB: a software environment for sequence data," Nucleic Acids Research, vol. 32, no. 4, pp. 1363-1371, 2004.

[23] T. Huber, G. Faulkner, and P. Hugenholtz, "Bellerophon: a program to detect chimeric sequences in multiple sequence alignments," Bioinformatics, vol. 20, no. 14, pp. 2317-2319, 2004.

[24] K. Katoh and H. Toh, "Recent developments in the MAFFT multiple sequence alignment program," Briefings in Bioinformatics, vol. 9, no. 4, pp. 286-298, 2008.

[25] T. A. Hall, "BioEdit: a user-friendly biological sequence alignment editor and analysis program for Windows 95/98/NT," in Proceedings of the Nucleic Acids Symposium Series, vol. 41, pp. 95-98, 1999.

[26] D. Posada, "jModelTest: phylogenetic model averaging," Molecular Biology and Evolution, vol. 25, no. 7, pp. 1253-1256, 2008.

[27] A. Stamatakis, P. Hoover, and J. Rougemont, "A rapid bootstrap algorithm for the RAxML web servers," Systematic Biology, vol. 57, no. 5, pp. 758-771, 2008.

[28] F. Ronquist, M. Teslenko, P. van der Mark et al., "MrBayes 3. 2: efficient Bayesian phylogenetic inference and model choice across a large model space," Systematic Biology, vol. 61, no. 3, pp. 539-542, 2012.

[29] M. Gouy, S. Guindon, and O. Gascuel, "Sea view version 4: a multiplatform graphical user interface for sequence alignment and phylogenetic tree building," Molecular Biology and Evolution, vol. 27, no. 2, pp. 221-224, 2010.

[30] K. Tamura, D. Peterson, N. Peterson, G. Stecher, M. Nei, and S. Kumar, "MEGA5: molecular evolutionary 12 genetics analysis using maximum likelihood, evolutionary distance, and maximum parsimony methods," Molecular Biology and Evolution, vol. 28, no. 10, pp. 2731-2739, 2011.

[31] Ø. Hammer, D. A. T. Harper, and P. D. Ryan, "Past: paleontological statistics software package for education and data analysis," Palaeontologia Electronica, vol. 4, no. 1, article 9, 2001.

[32] E. K. Costello, S. R. P. Halloy, S. C. Reed, P. Sowell, and S. K. Schmidt, "Fumarole-supported islands of biodiversity within a hyperarid, high-elevation landscape on socompa volcano, puna de atacama, andes," Applied and Environmental Microbiology, vol. 75, no. 3, pp. 735-747, 2009.

[33] T. Horath and R. Bachofen, "Molecular characterization of an endolithic microbial community in dolomite rock in the Central Alps (Switzerland)," Microbial Ecology, vol. 58, no. 2, pp. 290-306, 2009.

[34] B. Büdel, T. Darienko, K. Deutschewitz et al., "Southern African biological soil crusts are ubiquitous and highly diverse in drylands, being restricted by rainfall frequency," Microbial Ecology, vol. 57, no. 2, pp. 229-247, 2009.

[35] J. Neustupa and P. Škaloud, "Diversity of subaerial algae and cyanobacteria on tree bark in tropical mountain habitats," Biologia, vol. 63, no. 6, pp. 806-812, 2008.

[36] L. S. Khaybullina, L. A. Gaysina, J. R. Johansen, and M. Krautová, "Examination of the terrestrial algae of the Great Smoky Mountains National Park, USA," Fottea, vol. 10, no. 2, pp. 201-215, 2010.

[37] L. Hoffmann, L. Ector, and I. Kostikov, "Algal flora from limed and unlimed forest soils in the Ardenne (Belgium)," Systematics and Geography of Plants, vol. 77, no. 1, pp. 15-90, 2007.

[38] L. A. Amaral-Zettler, E. A. McCliment, H. W. Ducklow, and S. M. Huse, "A method for studying protistan diversity using massively parallel sequencing of V9 hypervariable regions of small-subunit ribosomal RNA Genes," PLoS ONE, vol. 4, no. 7, Article ID e6372, 2009. 

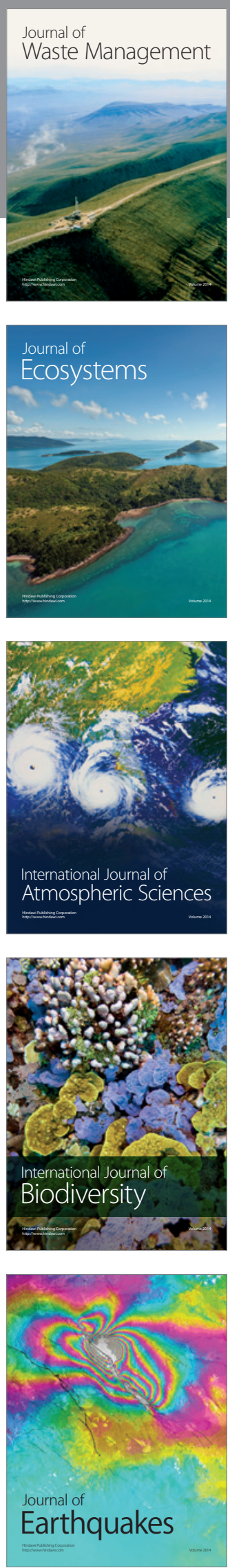
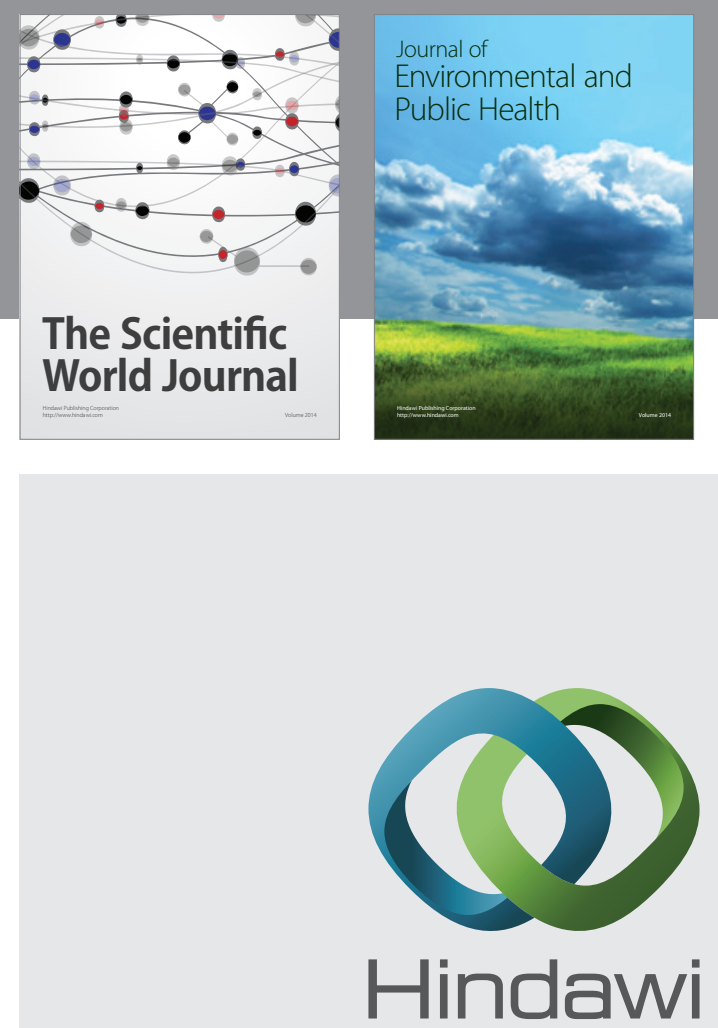

Submit your manuscripts at

http://www.hindawi.com
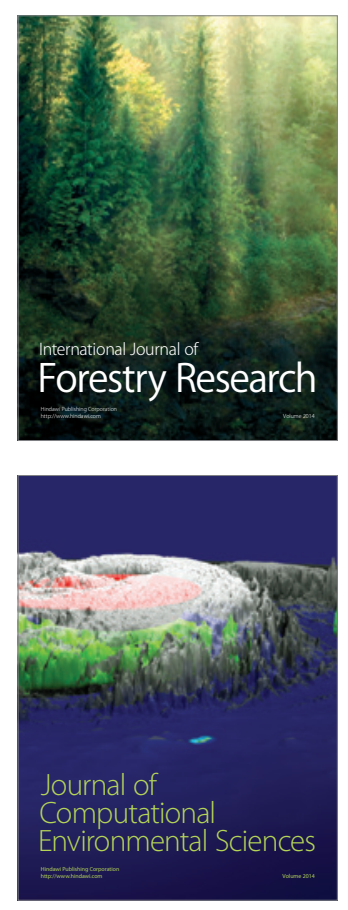
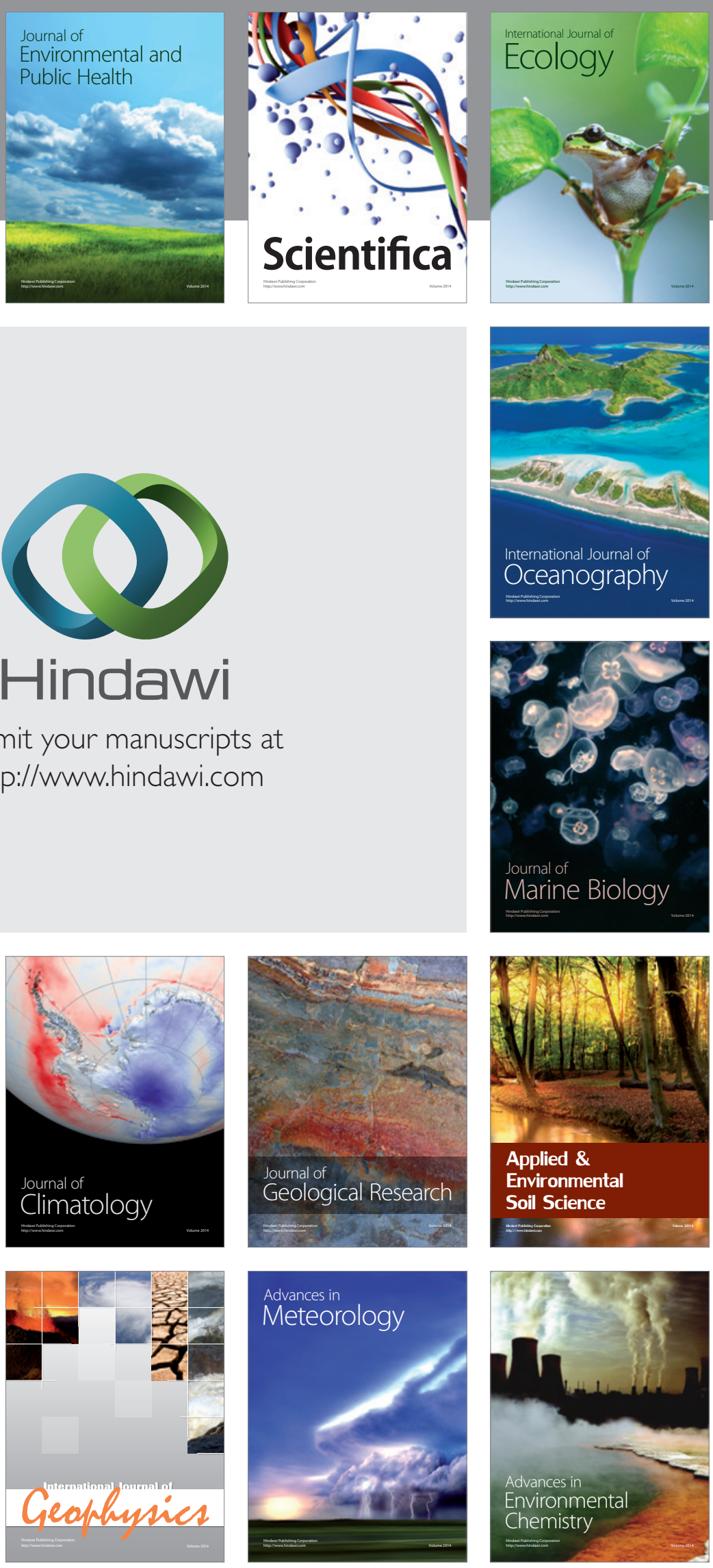